\title{
PHYSICO-CHEMICAL CHARACTERIZATION AND ANTIBACTERIAL ACTIVITY OF A CONTROLLED COLLAGEN- HYDROXYAPATITE-CIPROFLOXACIN RELEASE SYSTEM
}

\author{
MARIA-VIORICA CIOCÎLTEU ${ }^{1}$, OANA-LILIANA FILIP (IONESCU) ${ }^{1 *}{ }^{*}$, COSTEL VALENTIN $^{2}$ \\ MANDA $^{1}$, OANA-ELENA NICOLAESCU ${ }^{1}$, IONELA ANDREEA NEACȘU ${ }^{2}$, ANTON FICAI ${ }^{2}$, \\ IULIANA-MIHAELA BUZATU ${ }^{3}$, CLAUDIU NICOLICESCU ${ }^{4}$, OCTAVIAN CROITORU ${ }^{1}$, \\ JOHNY NEAMŢU ${ }^{1}$
}

\author{
${ }^{1}$ Faculty of Pharmacy, University of Medicine and Pharmacy of Craiova, 2-4 Petru Rareș Street, 200349, Craiova, Romania \\ ${ }^{2}$ Faculty of Applied Chemistry and Materials Science, University Politehnica of Bucharest, 1-7 Polizu Street, 01 1061, \\ Bucharest, Romania \\ ${ }^{3}$ Primary Physician, Fundeni Clinical Institute, Laboratory for Medical Analysis in the Microbiology Department, 258 \\ Fundeni Street, 022328, Bucharest, Romania \\ ${ }^{4}$ Department of IMST, Faculty of Mechanics, University of Craiova, 1 Călugăreni Street, 220037, Drobeta Turnu Severin, \\ Romania
}

*corresponding author: oanaionescu611@yahoo.com

Manuscript received: January 2020

\begin{abstract}
The aim of our study was to synthesize a biocomposite material using a natural polymer (collagen), hydroxyapatite and ciprofloxacin. We used Fourier-transform infrared spectroscopy (FT-IR), dynamic light scattering (DLS), high performance liquid chromatography (HPLC-DAD) and scanning electron microscopy (SEM) for the physico-chemical characterization and we determined its antibacterial activity against Staphylococcus aureus Rosenbach (S. aureus), Pseudomonas aeruginosa (Schroter) Migula (P. aeruginosa), Klebsiella pneumonia (Schroter) Trevisan (K. pneumoniae) and Escherichia coli (Migula) Castellani and Chalmers (E. coli). The release profile of the ciprofloxacin chemisorbed in the material was also studied, and we found that the release was sustained for 30 days.
\end{abstract}

\section{Rezumat}

Scopul acestui studiu a fost acela de a sintetiza un material biocompozit cu ajutorul unui polimer natural (colagen), hidroxiapatitei şi ciprofloxacinei. Pentru caracterizarea fizico-chimică s-au folosit spectroscopia în infraroşu cu transformată Fourier (FT-IR), DLS, HPLC-DAD şi microscopia electronică de baleiaj (SEM), în timp ce activitatea antibacteriană a materialului obținut a fost determinată pe Staphylococcus aureus, Pseudomonas aeruginosa, Klebsiella pneumonia şi Escherichia coli. Profilul de eliberare al ciprofloxacinei chemisorbite a fost de asemenea studiat, constatându-se o eliberare susţinută a antibioticului din material, pe o perioadă de 30 de zile.

Keywords: collagen-hydroxyapatite-ciprofloxacin, biocomposite, physico-chemical characterization, antibacterial activity

\section{Introduction}

In the last half century, progress in the development of new biomaterials and surgical implantation techniques has led to an explosive increase in their use in the form of implants or medical devices that play a role in restoring bone tissue integrity $[17,18]$. The biomaterials market uses over 300 billion dollars annually, with an increase of $20 \%$ annually [12]. A solution that is the focus of many research groups, in the field of biomaterials, is the local delivery of the antibiotic [4] by including it at the surface of the implant or by obtaining structures with local yield, which are implanted in the bone defects that result from infections. Thus, local antibiotic therapy improves cure rates in osteomyelitis [16], ciprofloxacin being one of the most commonly used antibiotics for Staphylococcus aureus infections.

Hydroxyapatite and its derivatives (calcium phosphates) exhibit superior mechanical characteristics, having an increased biocompatibility [15], thereby contributing intensively in the bone regeneration process $[6,11]$. The association of hydroxyapatite or its derivatives with collagen leads to significant changes that are reflected in the biological properties of the implant, respectively on the simulation of the osteogenesis process [3]. The biomimetic function of these biomaterials is also given by interactions of a supramolecular nature (hydrogen bonds, electrostatic forces, organic matrix packing effects etc.) or molecular assembly phenomena, explained as a result of the 
functional complementarity between the components of the composite [8,9].

The purpose of this study was the development of a collagen-hydroxyapatite-ciprofloxacin (Coll-HA-CIP) composite that would allow the production of bone allografts, with applications in the treatment of osteomyelitis.

\section{Materials and Methods}

\section{Materials}

All chemicals were of analytical grade and were purchased from Merck (Darmstadt, Germany) Coll-HA-CIP biocomposite, distilled water $(1 \mathrm{~mL})$, ciprofloxacin $15 \mu \mathrm{g}$, bacterial strains: isolated from hospitalized patients: Pseudomonas aeruginosa MDRO (Multi Drug Oral Resistance), Klebsiella pneumoniae MDRO, Klebsiella pneumoniae MSS (Multi Drug Sensitivity), Escherichia coli ESBL (Bacteria producing betalactamase), Escherichia coli MSS, Staphylococcus aureus MRSA (S. aureus methicillin resistant), Staphylococcus aureus MSSA (Staphylococcus aureus methicillin sensitive). Bacterial strains were isolated from haemocultures, collected from patients with haematological diseases, identified by current laboratory methods (Gram smear, oxidase test, coagulase test, citrate test, TSI-test, MIUtest) and automated methods (BD Phoenix and VITEK 2 SYSTEMS).

Sensitivity to therapy was tested using a huge number of antibiotics (Amoxicillin/Clavulanic Acid, Ceftriaxone, Cefepime, Ceftazidine, Ceftazidim/Avibactam, Imipenem, Meropenem, Ertapenem, Colistin, Gentamicin, Trimethoprim/Sulfametoxine, Cefametoxine, Sofametoxine, Vancomycin, Linezolid, Erythromycin, Clindamycin, Rifampicin and Tertacyclin), by diffusimetric method (Kirby Bauer) and by automatic method (automatic systems).

Synthesis of collagen-hydroxyapatite (Coll-HA) biocomposite

The synthesis of the Coll-HA biocomposite consists of the in situ generation of hydroxyapatite in the collagen matrix. For this purpose, a Coll-HA mixture was prepared with the mass ratio collagen pure substance/inorganic $\mathrm{mp}=1: 1$.

The collagen used is stable in acidic $\mathrm{pH}$, containing $2.26 \%$ pure (dry) substance.

Thus, in the collagen mixture maintained at low temperatures (to prevent denaturation), a suspension containing $\mathrm{Ca}^{2+}$ ions is added dropwise, the mixture being stirred for $30 \mathrm{~min}$ at $400 \mathrm{rpm}$. Subsequently, under careful temperature control, a $\mathrm{PO}^{4-}$ aniongenerating suspension is added gradually, the mixture being kept under mechanical stirring for another 30 minutes until the mixture is completely homogenized. The process is accompanied by precipitation of HA directly into the collagen matrix.

The inorganic precursors used were $\mathrm{Ca}(\mathrm{OH})_{2}$ and $\left(\mathrm{NH}_{4}\right)_{2} \mathrm{HPO}_{4}$. The obtained final mixture had a white, viscous appearance. For crosslinking, a dilute solution of Glutaraldehyde (1\%) was added to the mixture, and then stored at $4^{\circ} \mathrm{C}$ for $24 \mathrm{~h}$. After crosslinking, the composite was washed with ultrapure water repeatedly until neutral $\mathrm{pH}$ was established, then subjected to the lyophilisation process.

The gel thus obtained was subjected to the freezedrying process (freezing at $55^{\circ} \mathrm{C}$ for 12 hours, vacuuming at 0.001 mbar for 12 hours and heating under vacuum for 24 hours up to $35^{\circ} \mathrm{C}$ ), to obtain porous composite materials.

Chemisorption of ciprofloxacin

In order to achieve the chemisorption of ciprofloxacin in the Coll-HA composite, a solution of ciprofloxacin with a concentration of $3.33 \mathrm{mg} / \mathrm{mL}$ was prepared. Since ciprofloxacin is very slightly soluble in water, having a minimum solubility at $\mathrm{pH} 7.4(30 \mathrm{mg} / \mathrm{mL}$ at $20^{\circ} \mathrm{C}$ ), the $\mathrm{pH}$ was adjusted to 10.5 with $\mathrm{NH}_{4} \mathrm{OH}$ and ciprofloxacin was added while stirring (500 rpm). It was chosen to solubilize the drug in a basic medium, because an acidic $\mathrm{pH}$ would affect the hydroxyapatite in the composite.

The optimum contact time is the time required for the maximum adsorption of ciprofloxacin within a minimum contact time. Initially there is a rapid adsorption in the first hours after the start of the experiment, then the initial rate of adsorption decreases gradually, with increasing time and reaching equilibrium at about 48 hours.

\section{FT-IR analysis}

FT-IR spectra were recorded in potassium bromide, on a Fourier Avatar Nicolet spectrophotometer in the range of $500-4000 \mathrm{~cm}^{-1}$.

DLS analysis

DLS analysis was accomplished with a Brookhaven 90 plus/bi-mas multi angle particle sizing option with the following characteristics: size range: $2 \mathrm{~nm}$ to $3 \mu \mathrm{m}$, diffusion coefficient range: $10^{-6}$ to $10^{-9} \mathrm{~cm}^{2} / \mathrm{sec}$, accuracy: $\pm 1 \%$ to $2 \%$ with dust free samples, laser: $15 \mathrm{~mW}$ solid state laser, red temperature control: 5 to $75^{\circ} \mathrm{C}$, sample volume: 0.5 to $3 \mathrm{~mL}$.

The zeta potential was measured with a Zeta potential Analyzer (Brookhaven) with the following characteristics: zeta potential Range: -150 to $+150 \mathrm{mV}$, size range: $10 \mathrm{~nm}$ to $30 \mu \mathrm{m}$, accuracy: $\pm 2 \%$, repeatability: $\pm 2 \%$, laser: $35 \mathrm{~mW}$ solid state laser, red $(660 \mathrm{~nm}$ wavelength), temperature control: 6 to $74^{\circ} \mathrm{C}$, sample volume: $1.5 \mathrm{~mL}$.

HPLC-DAD loading efficiency

The determination of ciprofloxacin was performed by HPLC on a Thermo Finnigan Surveyor chromatograph with a DAD detector and a Thermo Finnigan Xcalibur software. Work was carried out on a Hypersil GOLD C18 (Thermo Scientific) column, $250 \mathrm{~mm}$ long, $4.6 \mathrm{~mm}$ inside diameter, with a particle size of $5 \mu \mathrm{m}$ stationary phase. The mobile phase consisted of a mixture of $20 \mathrm{mM}$ citrate buffer solution (containing $16.7 \mathrm{mM}$ citric acid dihydrate and $3.3 \mathrm{mM}$ sodium citrate di- 
hydrate) - acetonitrile (40:60, v/v) with a flow rate of $1 \mathrm{~mL} / \mathrm{min}$.

The standard ciprofloxacin solution at $1 \mathrm{mg} / \mathrm{mL}$ concentration was solubilized in acetonitrile. From this solution, by dilution, other solutions with concentrations of $125,250,500,1000,2000,5000$, 7500 and $20000 \mathrm{ng} / \mathrm{mL}$ were prepared.

In vitro release of ciprofloxacin

The temperature was maintained at $37^{\circ} \mathrm{C} \pm 0.5^{\circ} \mathrm{C}$. Bottles with threaded stopper were used to ensure the samples are watertight to avoid water evaporation. Initially $10 \mathrm{~mL}$ of HPLC ultrapure water (LiChrosolv, Merck) was added and then Coll-HA-CIP disks were immersed.

At regular time intervals ( 1 day, 3 days, 6 days, 10 days, 21 days and 30 days respectively), $0.5 \mathrm{~mL}$ solution was taken for quantitative determination of ciprofloxacin by HPLC. The volume taken was replaced with the yield medium (ultrapure water) to avoid saturation of the solution in ciprofloxacin.

\section{HPLC method}

\section{The mobile phase}

To prepare $1 \mathrm{~L}$ mobile phase, $640 \mathrm{~mL}$ of acetonitrile, $20 \mathrm{~mL}$ of methanol and $340 \mathrm{~mL}$ of water were mixed, in which $1.20 \mathrm{~g}$ of citric acid and $0.330 \mathrm{~g}$ of monosodium citrate were solubilized.

$50 \mu \mathrm{L}$ of the sample taken were brought to $5 \mathrm{~mL}$ with mobile phase and $20 \mu \mathrm{L}$ of the mixture was injected into the HPLC system.

\section{Morphology}

Scanning electron microscopy was performed in order to highlight aspects related to the morphology of the samples, such as the size, particle shape, tendency of agglomeration and porosity. The acquisition of micrographs was done with the help of a highresolution scanning electron microscope, FEI Inspect $\mathrm{F} 50$, at $30 \mathrm{KeV}$ voltage and various magnifications. Because the analysed samples do not have electrical conductivity, a preparation consisting of a metallization process (coating the surface to be analysed with a film of $\mathrm{Au}$ particles of about $4 \mathrm{~nm}$ thickness) is required. This process of obtaining electrical conductivity takes 60 seconds. The samples were then fixed to an aluminium support using a double carbon adhesive tape (also conductor). The analysis is performed in vacuum, by measuring the energy of the secondary electrons resulting from the interaction of the surfaces with the primary electron beam.

\section{Antibacterial activity}

The composite was weighed to determine the amount of antibiotic to be tested (CIP). The test product was inoculated in $1 \mathrm{~mL}$ of distilled water and the incubation was accomplished at room temperature for $24 \mathrm{~h}$.

The 0.5 Mc Farland nephelometer standard bacterial strain test was performed (using 3 - 5 colonies of Pseudomonas aeruginosa, Klebsiella pneumoniae,
Escherichia coli in $1 \mathrm{~mL}$ physiological serum sowed on the standard Muller Hilton placemat Agar (MHA). From the suspension of each test product, $0.20 \mu \mathrm{L}$ of each inoculum of bacterial strain was inoculated. After incubation at $37^{\circ} \mathrm{C}$ for $24 \mathrm{~h}$, the results were read. We previously tested the CIP action of known concentrations on the bacterial strains studied, comparing the results of the antimicrobial action with the CLSI standard guideline (Clinical and Laboratory Standards Institute).

\section{Results and Discussion}

\section{FT-IR analysis}

The FT-IR spectrum obtained for the synthesized biocomposite presents several peaks belonging to the hydroxyapatite: thus, at $564 \mathrm{~cm}^{-1}, 606 \mathrm{~cm}^{-1}$ and $1036 \mathrm{~cm}^{-1}$ sharp peaks characteristic of the vibrations of the $\mathrm{PO}^{4-}$ group in the HA structure were observed, while between $3500-3600 \mathrm{~cm}^{-1}$ a broad band was identified, probably due to the stretch vibration of the hydroxyl group in the HA structure. Comparing the wavelengths at which these characteristic peaks of hydroxyapatite appear in the obtained composite with those of the commercial hydroxyapatite spectrum used as a standard, it was observed that in the CollHA-CIP biocomposite they appear at identical wave numbers, which leads us to the conclusion that between the $\mathrm{Ca}$ atoms of HA and ciprofloxacin inserted by chemisorption into the biocomposite there are no strong chemical bonds, which would have led to a shift of the frequencies in the spectrum, but rather weak intermolecular attraction forces.

Based on this, we can assume that the release is mainly controlled by the diffusion and solubility into the aqueous solution, but, because of the low solubility of Ciprofloxacin in water, the release is sustainable. In the FT-IR spectrum of commercial ciprofloxacin (Sigma Aldrich, Germany), the peak at $1616 \mathrm{~cm}^{-1}$ characteristic to $-\mathrm{C}=\mathrm{O}$ bond of ciprofloxacin is observed [7]. The peak of Coll-HA-CIP is shifted to about $1630 \mathrm{~cm}^{-1}$, which may be due to the binding of the calcium ions from HA to ciprofloxacin by carbonyl oxygen of ciprofloxacin.

At 2840 - $2845 \mathrm{~cm}^{-1}$, both in the spectrum of ciprofloxacin (higher intensity) and in the spectrum of the composite (lower intensity), a band characteristic to the vibration of the $\mathrm{N}$ atom in the piperazinyl group is observed. The lower intensity band in the composite spectrum indicates a zwitterionic form of the nitrogen atom, so this atom cannot make coordinative bonds with the calcium ions. The fact that ciprofloxacin is found as an amphion in biocomposite is also characterized by the absence of the symmetrical stretch vibration of the carboxylic group [19], a vibration that is present in the spectrum of pure ciprofloxacin at 1375 $\mathrm{cm}^{-1}$ next to that of asymmetrical stretch at $1590 \mathrm{~cm}^{-1}$. 
HPLC loading efficiency

The equation of the calibration curve was $\mathrm{y}=1014 \mathrm{x}$ 177196 , having a very good regression coefficient, $\mathrm{R}^{2}=0.99993$. Detection was performed at $280 \mathrm{~nm}$, with a retention time of 3.2 minutes for standard ciprofloxacin.

After 48 hours of adsorption, a smaller amount of ciprofloxacin remained in solution, the remainder being bound to hydroxyapatite in the composite.

Calculating the amount of chemisorbed ciprofloxacin $(62.7 \mathrm{mg})$ and reporting it to the hydroxyapatite-collagen mass immersed in the solution, the percentage of bound ciprofloxacin was found to be $18.027 \%$, similar to other methods of binding ciprofloxacin to hydroxyapatite such as adding the drug during the process of synthesis of hydroxyapatite by wet precipitation. A possible major contribution to the high percentage of drug that can bind to the composite is also the porosity of the composite given by the pore forming capacity of collagen gel, which implicitly leads to an increase of the contact surface as well as of the diffusion rate.
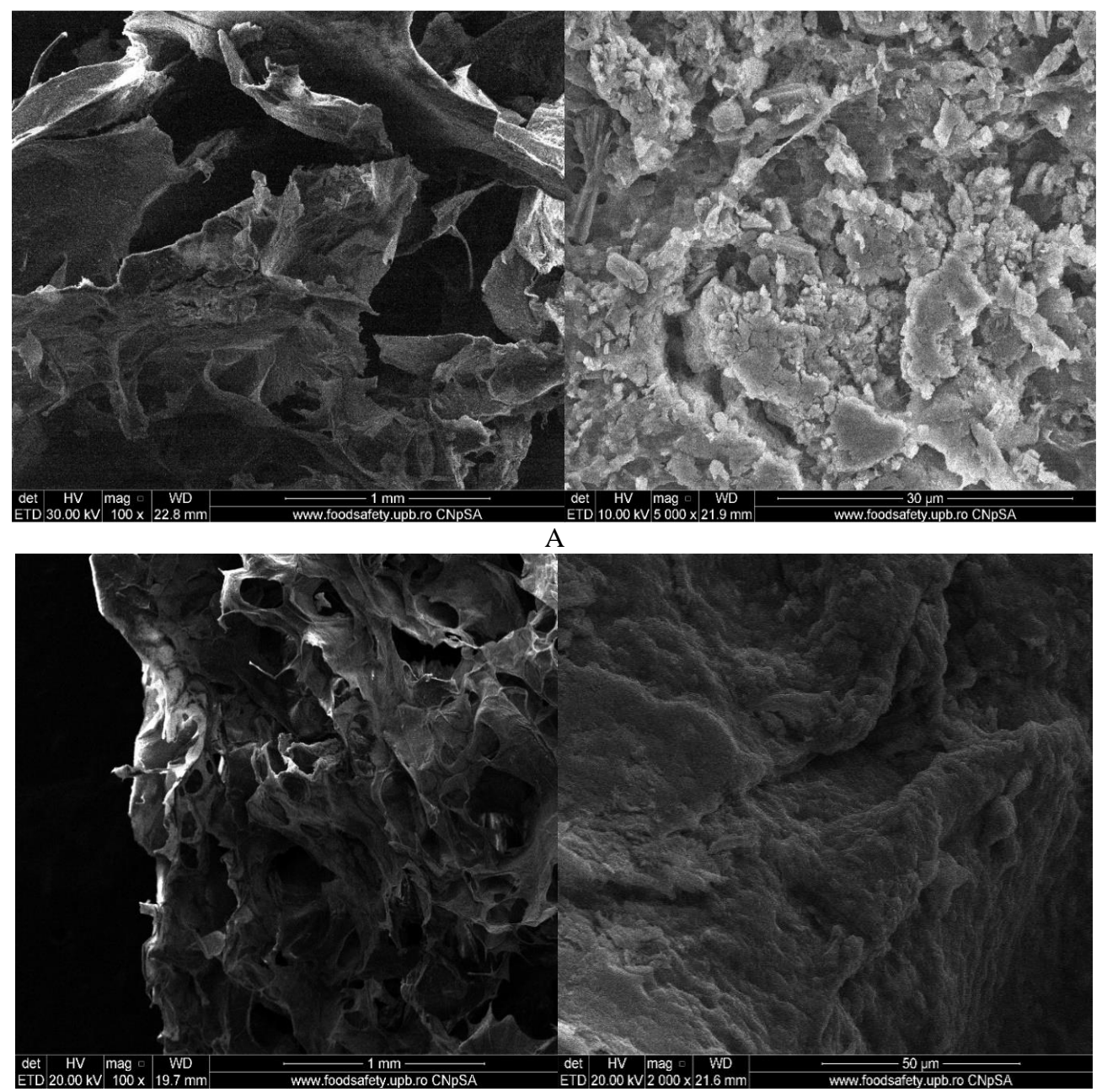

B

Figure 1.

A) SEM images for the Coll-HA composite material; B) Coll-HA-CIP composite material

\section{Morphology}

Figure 1 shows the SEM images for colloidal porous composites, obtained by lyophilisation. In the left images for each sample, made at small magnifications, of $100 \times$, one can see the three-dimensional structure of the collagen-based composite suprastructure. The lyophilized collagen-based composite matrix has interconnected pores, making it an ideal candidate for bone regeneration support, the pore size being large enough to allow cells in growth without altering very much the mechanical properties, the size of the pores being below $150 \mu \mathrm{m}[2,10]$

At higher magnifications, one can notice the collagen fibres [14], interlaced, having the appearance of a folded sheet, in the case of all the analysed materials. In all 3 samples the collagen matrix is mineralized with hydroxyapatite particles, evidenced by the presence of large agglomerates, both on the surface and inside the porous materials, demonstrating their homogeneous distribution, due to the in situ method of obtaining HA in the Coll matrix [7]. Adding drugs does not 
FARMACIA, 2020, Vol. 68, 6

substantially alter the morphology of the material, the active substance being most likely absorbed inside the pores or adsorbed on the surface of HA.

Antibacterial activity

By reading the sensitivity diameters after $24 \mathrm{~h}$ it was observed that all test products had antibacterial action
(Table I) on the following strains: Klebsiella MDRO, Klebsiella MSS, E. coli ESBL, E. coli MSS, S. aureus MRSA, S. aureus MSSA, and resistance on Pseudomonas MDRO strains (for all products tested) and Klebsiella MDRO for standard ciprofloxacin.

Table I

Antibacterial activity of Coll-HA-CIP biocomposite

\begin{tabular}{|l|c|c|c|}
\hline \multicolumn{1}{|c|}{ Strains } & \multicolumn{3}{c|}{ Inhibition diameter of standard ciprofloxacin } \\
\hline Klebsiellla MDRO & Contact resistance & Contact resistance & Contact resistance \\
\hline Klebsiella MSS & $40 \mathrm{~mm}$ & $40 \mathrm{~mm}$ & Resistant \\
\hline Escherichia coli ESBL & $41 \mathrm{~mm}$ & $46 \mathrm{~mm}$ & Resistant \\
\hline Escherichia coli MSS & $38 \mathrm{~mm}$ & $32 \mathrm{~mm}$ & Resistant \\
\hline S. aureus MRSA & $31 \mathrm{~mm}$ & $30 \mathrm{~mm}$ & Resistant \\
\hline S. aureus MSSA & $31 \mathrm{~mm}$ & $32 \mathrm{~mm}$ & Resistant \\
\hline
\end{tabular}

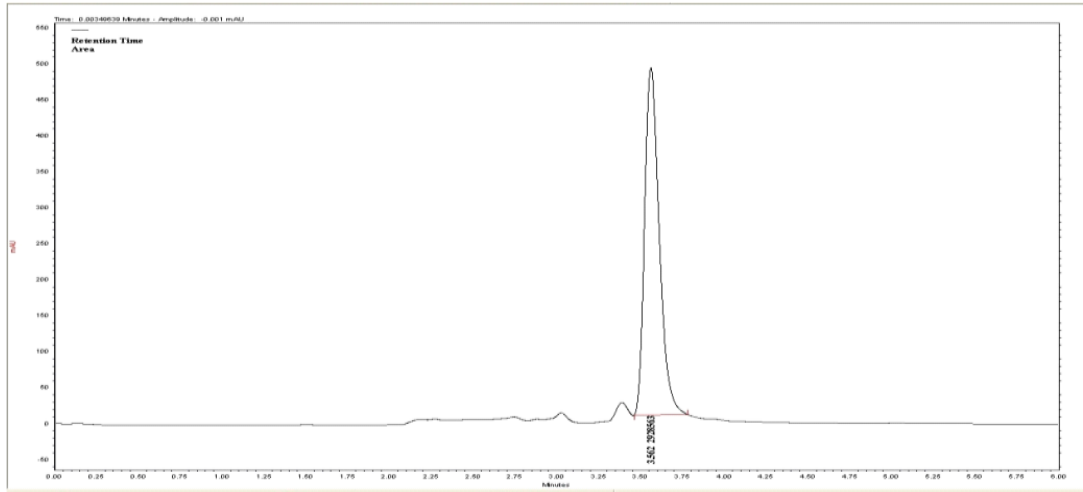

A

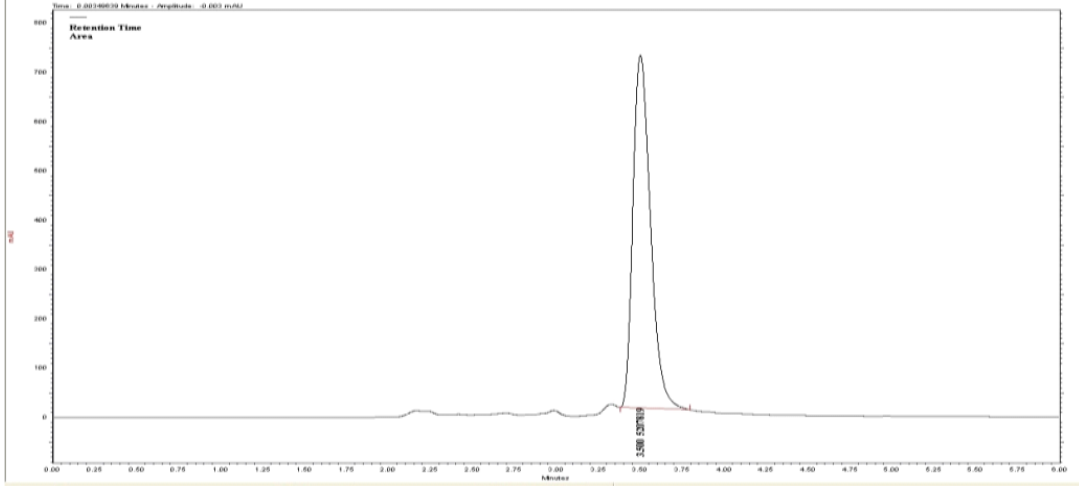

B

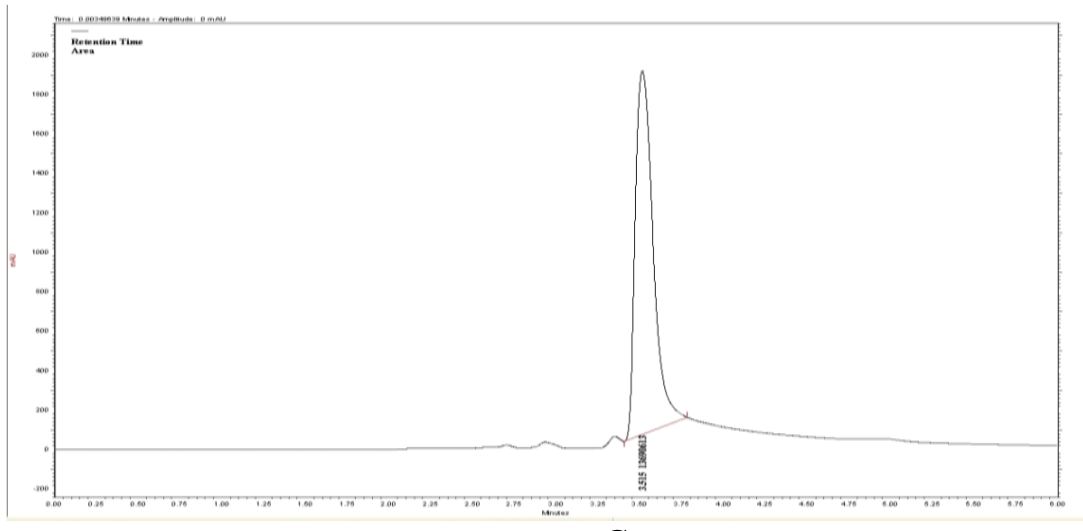

C

Figure 2.

Chromatograms obtained at the release of ciprofloxacin from the Coll-HA-CIP composites: A) at 1 day; B) 21 days; C) 30 days 
FARMACIA, 2020, Vol. 68, 6

Release of ciprofloxacin from the collagen-hydroxyapatite-ciprofloxacin composite

Prolonged release of ciprofloxacin from ciprofloxacinbased compositions was observed by others [1, 3, 15], who successfully synthesized a composite with a 60-day antibiotic release period. Rauschmann et al. studied the release of ciprofloxacin from a compound based on hydroxyapatite and calcium sulphate and found a release period of only 10 days [11], while from the usual drug tablets, ciprofloxacin is released within 4 - 6 hours after administration [5].

Figure 2 shows the chromatograms (diluted sample 1:10) related to ciprofloxacin release at 1 day, 21 days and 30 days respectively.

According to our results, in the first 10 days ciprofloxacin is released by the Coll-HA-CIP composite (which contains $18.027 \%$ ciprofloxacin) in a percentage of $32 \%$. The amount of antibiotic released reached $89 \%$ by the end of the study.

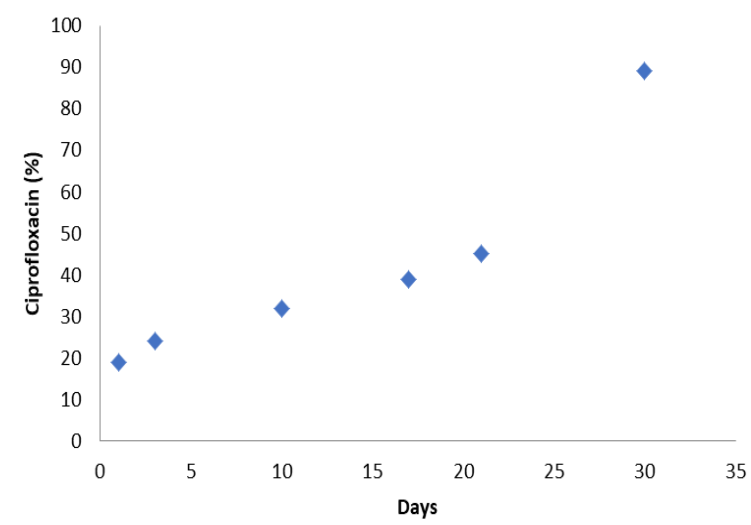

Figure 3.

Release of ciprofloxacin from Coll-HA-CIP

This slow release profile (Figure 3) for the first part of the study may be due to the links that are formed between ciprofloxacin and hydroxyapatite in the synthesis process [19]. The faster release after 20 days is most probably induced by the moderate degradation of the collagen matrix which means that the release rate increases because of the symbiosis of diffusion and bioerosion.

\section{Conclusions}

The biocomposite material Coll-HA could stimulate the osteogenesis process due to the special characteristics that both collagen and hydroxyapatite possess (biocompatibility, osteoconductivity, lack of toxicity). In the present paper we chose ciprofloxacin as an antibiotic due to the antibacterial spectrum against most of the specific pathogens found in bone infections, with a very low minimum inhibitory concentration (MIC) $(0.25-2 \mu \mathrm{g} / \mathrm{mL})$. Its release from the composite material is slow, over a long period of time.

\section{Conflict of interest}

The authors declare no conflict of interest.

\section{References}

1. Akinleye MO, Jolaoso AA, Coker HAB, Comparative dissolution profiles of representative quinolones in different media. Nig Q J Hosp Med., 2011; 21(1): 1-8.

2. Andronescu E, Ficai A, Georgiana M, Mitran V, Sonmez M, Ficai D, Ion R, Cimpean A, Collagenhydroxyapatite/Cisplatin Drug Delivery Systems for Locoregional Treatment of Bone Cancer. Tech Cancer Res Treat., 2013; 12(4): 275-284.

3. Becker PL, Smith RA, Williams RS, Dutkowsky JP, Comparison of antibiotic release from polymethylmethacrylate beads and sponge collagen. J Orthop Res., 1994; 12(5): 737-741.

4. Ciocîlteu MV, Podgoreanu P, Delcaru C, Chifiriuc MC, Manda CV, Biţă A, Popescu M, Amzoiu E, Croitoru O, Bleotu C, Bostan M, Neamţu J, PLGAGentamicin biocomposite materials with potential antimicrobial applications in orthopaedics. Farmacia, 2019; 67(4): 580-585.

5. Ciocîlteu MV, Mocanu AG, Mocanu A, Ducu C, Nicolaescu OE, Manda VC, Turcu-Stiolica A, Nicolicescu C, Melinte R, Balasoiu M, Croitoru O, Neamtu J, Hydroxyapatite-ciprofloxacin delivery system: Synthesis, characterisation and antibacterial activity. Acta Pharm., 2018; 68(2): 129-144.

6. Neut D, Dijkstra RJB, Thompson JI, Kavanagh C, van der Mei HC, Busscher HJ, A biodegradable gentamicinhydroxyapatite-coating for infection prophylaxis in cementless hip prostheses. Eur Cell Mater, 2015; 29: 42-56.

7. Deacon GB, Phillips RJ, Relationships between the carbon-oxygen stretching frequencies of carboxylate complexes and the type of carboxylate coordination. Coord Chem Rev., 1980; 33(3): 227-250.

8. Head WC, Bauk DJ, Emerson RH, Titanium as the material of choice for cementless femoral components in total hip arthroplasty. Clin Orthop Rel Res., 1995; 311: 85-90.

9. Ionescu (Filip) OL, Ciocîlteu MV, Manda CV, Neacsu IA, Ficai A, Amzoiu E, Turcu-Stiolica A, Croitoru O, Neamtu J, Bone - Graft Delivery Systems of Type PLGA-gentamicin and Collagen - hydroxyapatite gentamicine. Mater Plast., 2019; 56(3): 534-537.

10. Murphy CM, Haugh MG, O'Brien FJ, The effect of meanpore size on cell attachment, proliferation and migration in collagen-glycosaminoglycan scaffolds for bone tissue engineering. Biomaterials, 2010; 31(3): 461-466.

11. Rauschmann MA, Wichelhaus TA, Stirnal V, Dingeldein E, Zichner L, Schnettler R, Alt V, Nanocrystalline hydroxyapatite and calcium sulphate as biodegradable composite carrier material for local delivery of antibiotics in bone infections. Biomaterials, 2005; 26(15): 26772684.

12. Santavirta S, Gristina A, Konttinen YT, Cemented versus cementless hip arthroplasty: a review of prosthetic biocompatibility. Acta Orthop Scand., 1992; 63(2): 225-232. 
13. Stigter M, de Groot K, Layrolle P, Incorporation of tobramycin into biomimetic hydroxyapatite coating on titanium. Biomaterials, 2002; 23(20): 4143-4153.

14. Schwarz F, Bieling K, Latz T, Nuesry E, Becker J, Healing of intrabony peri-implantitis defects following application of a nanocrystalline hydroxyapatite (Ostim) or a bovine-derived xenograft (Bio-Oss) in combination with a collagen membrane (Bio-Gide). A case series. J Clin Periodontol., 2006; 33(7): 491-499.

15. Suresh KG, Govindana R, Girija EK, In situ synthesis, characterization and in vitro studies of ciprofloxacin loaded hydroxyapatite nanoparticles for the treatment of osteomyelitis. J Mater Chem B., 2014; 2(31): 5052-5060.

16. Tone A, Nguyen S, Devemy F, Topolinski H, Valette M, Cazaubiel M, Fayard A, Beltrand E, Lemaire C, Senneville E, Six-week versus twelve-week antibiotic therapy for nonsurgically treated diabetic foot osteomyelitis:
A multicenter open-label controlled randomized study. Diabetes Care, 2015; 38(2): 302-307.

17. Turcu-Stiolica A, Bubulica MV, Nicolaescu OE, Croitoru O, Popescu M, Manda VC, Simionescu A, Neamtu J, A design of experiment approach to the synthesis of alendronate-incorporated hydroxyapatite. Rev Chim., 2018; 69(8): 1944-1948.

18. Muţ AM, Vlaia L, Coneac G, Olariu I, Vlaia V, Popoiu C, Hîrjău M, Lupuliasa D, Novel topical chitosan/hydroxypropylmethylcellulose - based hydrogels containing fluconazole and sucrose esters. Formulation, physicochemical characterization, in vitro drug release and permeation. Farmacia, 2018; 66(1): 59-69.

19. Upadhyay SK, Kumar P, Arora V, Complexes of quinolone drugs norfloxacin and ciprofloxacin with alkaline earth metal perchlorates. J Struct Chem., 2006; 47(6): 1078-1083. 